Article

\title{
Rheology and Curability Characterization of Photosensitive Slurries for 3D Printing of $\mathrm{Si}_{3} \mathrm{~N}_{4}$ Ceramics
}

\author{
Xingbang Li ${ }^{1,2, *} \mathbb{C}$, Jingxian Zhang ${ }^{1,2, *}$, Yusen Duan ${ }^{1,2}$, Ning Liu ${ }^{1}$, Jinhua Jiang ${ }^{1}$, Ruixin Ma ${ }^{1}$, \\ Hongan $\mathrm{Xi}^{2}$ and Xiaoguang $\mathrm{Li}^{1}$ \\ 1 State Key Laboratory of High Performance Ceramics and Superfine Microstructure, Shanghai Institute of \\ Ceramics, Chinese Academy of Sciences, Shanghai 200050, China; duanyusen@mail.sic.ac.cn (Y.D.); \\ liuning@student.sic.ac.cn (N.L.); jiangjinhua@shu.edu.cn (J.J.); 1000459010@smail.shnu.edu.cn (R.M.); \\ lixiaoguang@mail.sic.ac.cn (X.L.) \\ 2 Center of Materials Science and Optoelectronics Engineering, University of Chinese Academy of Sciences, \\ Beijing 100049, China; xihongan@mail.sic.ac.cn \\ * $\quad$ Correspondence: lixingbang@mail.sic.ac.cn (X.L.); jxzhang@mail.sic.ac.cn (J.Z.); Tel.: +86-21-52412167 (J.Z.)
}

Received: 27 July 2020; Accepted: 9 September 2020; Published: 16 September 2020

\begin{abstract}
Among a series of 3D printing techniques, stereolithography provides a new route to produce ceramic architectures with the advantages of high-precision and short cycle time. However, up to now the stereolithography of non-oxide ceramics still face complex and difficult problems. This work focused on the analysis of rheological and curing ability of $\mathrm{Si}_{3} \mathrm{~N}_{4}$ photocurable slurries. The effects of monomer type, coarse silicon powder, solid loading and ambient temperature on the rheological behavior were intensively studied. The relationships between powder characteristic (involving refractive index, absorbance and the introduce of coarse silicon powder), monomer type and curing ability were discussed in detail. It is expected that this study may benefit the development of $\mathrm{Si}_{3} \mathrm{~N}_{4}$ or other non-oxide ceramic slurries for stereolithography.
\end{abstract}

Keywords: silicon nitride; ceramic stereolithography; rheological performance; curing properties

\section{Introduction}

Silicon nitride $\left(\mathrm{Si}_{3} \mathrm{~N}_{4}\right)$ ceramic exhibits a combination of outstanding mechanical, thermal, and physiochemical properties etc., and thus has been researched intensively for more than 60 years [1-3]. The excellent comprehensive performance made $\mathrm{Si}_{3} \mathrm{~N}_{4}$ ceramic to be considered as one of the most promising structural and functional material for a wide range of applications even in elevated temperatures or under harsh environments, including automotive engines parts, ball bearings, heat exchangers, ceramic substrates for power electronic, and ceramic armor [4-6].

Due to the growing increase of the high-performance and complex-shaped ceramic parts demands from advanced technology areas, much more attention is now being paid to the ceramic additive manufacturing techniques which can fabricate physical parts in a discrete point-by-point, line-by-line or layer-by-layer additive manner [7]. Among these techniques, ceramic stereolithography (CSL) involving photopolymerization of ceramic suspensions to pattern the layers has the advantages of high-precision and short cycle time [8]. In addition, it also belongs to near-net shaping technology, which does not require post forming processing and so can reduce production costs. Digital light processing (DLP) is a variant of this technique. It uses a projector to selectively expose an entire cross-sectional slice from CAD software on the photosensitive resin surface at each given time, which shows faster build speeds than early stereolithography technology in which the surface of the resin is scanned by a laser beam [9]. By now, numerous researches concerning slurry preparation, 
optimization of processing parameters and heat treatment about the stereolithography fabrication of many kinds of oxide ceramics, such as $\mathrm{Al}_{2} \mathrm{O}_{3}$ [10-15], $\mathrm{ZrO}_{2}$ [16-20], ZTA [21-23], $\mathrm{SiO}_{2}$ [24-26], and other ceramics with light color [27-30] have been widely reported. However, the photo-shaping method of non-oxide ceramics (often in deeper color) still faces tough challenges.

Griffith et al. [31,32] firstly used stereolithography technique to produce ceramics and deduced the corresponding formulas basing upon the Beer-Lambert law, from which the relationship between cure depth $\left(C_{d}\right)$, average particle size $(d)$, volume fraction $(\Phi)$, scattering efficiency term $(Q)$, incident light intensity $\left(E_{0}\right)$ and the minimum intensity required to achieve photocuring $\left(E_{c}\right)$ is revealed:

$$
C_{d} \propto \frac{d}{\Phi} \frac{1}{Q} \ln \frac{E_{0}}{E_{c}}
$$

where $Q$ is a function of the refractive index difference between ceramic powder and the photocurable liquid media:

$$
Q=\beta\left(n_{\text {ceramic }}-n_{\text {solution }}\right)^{2}
$$

In their work they also tried to shape $\mathrm{Si}_{3} \mathrm{~N}_{4}$ but failed, and they attributed it to the high refractive index of $\mathrm{Si}_{3} \mathrm{~N}_{4}$ powder $\left(n_{S_{3} \mathrm{~N}_{4}}=2.1\right)$ which resulted in poor cure depth. He and Ding $[33,34]$ pointed out that the larger the absorbance value of ceramic powder, the worse curing behavior of slurry will exhibit. They observed that the curing ability of SiC slurries increased with the increasing of particle size and the decreasing of solid loading. Finally, they successfully prepared gray-colored SiC ceramic green body with pyramid and hollowed basket structures, by using a maximum solid loading of 35 vol.\% slurry in which the $15 \mu \mathrm{m}$ coarse SiC powder was dispersed. Huang et al. [35] used DLP method to fabricate $\mathrm{Si}_{3} \mathrm{~N}_{4}$ gear with a relative density $\geq 90 \%$ by means of surface oxidation of $\mathrm{Si}_{3} \mathrm{~N}_{4}$ powder. They reported that as the oxidation degree of $\mathrm{Si}_{3} \mathrm{~N}_{4}$ powder increased, the light absorbance and refractive index both reduced. Liu et al. [36] found that the maximum solid loading of the $\mathrm{Si}_{3} \mathrm{~N}_{4}$ slurry can be improved notably from 35 vol. $\%$ to 45 vol. \% by the surface modification of submicron $\mathrm{Si}_{3} \mathrm{~N}_{4}$ powder with the silane coupling agent $\mathrm{KH} 560$. They discussed the effects of applied energy dose and solid loading on cure depth of $\mathrm{Si}_{3} \mathrm{~N}_{4}$ slurries in their paper, however, there are also many other factors which were not mentioned by them. Wang et al. [37] fabricated complicated $\mathrm{Si}_{3} \mathrm{~N}_{4}$ ceramic parts through polymer-derived ceramics (PDCs) route by using a blend of liquid photocurable polysilazane and acrylic resin without ceramic particles added as raw material. Although it is a novel method to form $\mathrm{Si}_{3} \mathrm{~N}_{4}$ green body, this route did not involve the questions about the dispersion of powder and the scattering and absorption of light produced by the interaction of incident light with ceramic particles.

Therefore, the emphasis of this study was put on the shaping of $\mathrm{Si}_{3} \mathrm{~N}_{4}$ green parts through DLP-based stereolithography by using ceramic powder not the precursor. The effects of powder characteristics, solid loading, monomer type and temperature on the slurries' performance (rheological behavior and curing ability) were analyzed in detail. Finally, $\mathrm{Si}_{3} \mathrm{~N}_{4}$ ceramic green parts with complex shapes were successfully fabricated. The study of binder burn-out and sintering, as well as mechanical performance, has to be further investigated in more detail in our future work.

\section{Materials and Methods}

The raw materials used in this study are listed in Table 1. All the information of raw materials was provided by their suppliers. The slurry designations and corresponding compositions are outlined in Table 2 . The yttria-alumina $\left(\mathrm{Y}_{2} \mathrm{O}_{3}-\mathrm{Al}_{2} \mathrm{O}_{3}\right)$ system is the most widely applied sintering aid system for the facilitation of liquid phase sintering in $\mathrm{Si}_{3} \mathrm{~N}_{4}$ at low temperature $\left(<1800{ }^{\circ} \mathrm{C}\right)$ to achieve densification $[38,39]$. The amounts of sintering additives in the $\mathrm{Si}_{3} \mathrm{~N}_{4}$ and $\left(\mathrm{Si}_{3} \mathrm{~N}_{4}+\mathrm{Si}\right)$ slurries were calculated in order to yield a fully nitrided green body with a nominal composition of $\mathrm{Si}_{3} \mathrm{~N}_{4}: \mathrm{Y}_{2} \mathrm{O}_{3}$ : $\mathrm{Al}_{2} \mathrm{O}_{3}=93: 5: 2$ at mass ratio. BYK-103 was used as the dispersant to stabilize ceramic particle, with a weight content (relative to the total powder mass) of $3 \mathrm{wt} . \%$. The acrylate monomers (HDDA and NPG2PODA) and photoinitiator (TPO-L) all belonged to free radical polymerization system. 
Table 1. Data of the raw materials.

\begin{tabular}{|c|c|c|c|c|}
\hline Material & State & Usage & Description & Supplier \\
\hline $\mathrm{Si}_{3} \mathrm{~N}_{4}$ powder & Solid & Filler & $\mathrm{D}_{50}=0.5 \mu \mathrm{m}$, gray color & Qinhuangdao Eno Material Co., Ltd. \\
\hline $\mathrm{Si}_{3} \mathrm{~N}_{4}$ powder & Solid & Filler & $\mathrm{D}_{50}=0.55 \mu \mathrm{m}$, gray color & Denka Co., Ltd. \\
\hline $\mathrm{Si}_{3} \mathrm{~N}_{4}$ powder & Solid & Filler & $D_{50}=0.65 \mu \mathrm{m}$, gray color & Ube Industries Co., Ltd. \\
\hline Si powder & Solid & Filler & $\mathrm{D}_{50}=5 \mu \mathrm{m}$, black color & Xuzhou Lingyun Silicon Industry Co., Ltd. \\
\hline $\mathrm{Y}_{2} \mathrm{O}_{3}$ powder & Solid & Sintering additive & $\mathrm{D}_{50}=0.5 \mu \mathrm{m}$, white color & Shanghai yuekai metal material Co., Ltd. \\
\hline $\mathrm{Al}_{2} \mathrm{O}_{3}$ powder & Solid & Sintering additive & $\mathrm{D}_{50}=0.4 \mu \mathrm{m}$, white color & Alteo \\
\hline $\mathrm{ZrO}_{2}$ powder & Solid & Filler & $\mathrm{D}_{50}=0.6 \mu \mathrm{m}$, white color & Tosoh Corp. \\
\hline HDDA & Liquid & Binder & Di-functional acrylate, $\mathrm{M}_{\mathrm{w}} \sim 226 \mathrm{~g} / \mathrm{mol}$, viscosity is $5 \sim 10 \mathrm{mPa} \cdot \mathrm{s}$ & DSM \\
\hline NPG2PODA & Liquid & Binder & Di-functional acrylate, $\mathrm{M}_{\mathrm{w}} \sim 328 \mathrm{~g} / \mathrm{mol}$, viscosity is $10 \sim 20 \mathrm{mPa} \cdot \mathrm{s}$ & DSM \\
\hline PEG-400 & Liquid & Diluent & Polyethylene glycol & Aladdin \\
\hline TPO-L & Liquid & Photoinitiator & ethyl(2,4,6-trimethylbenzoyl)-phenyl phosphinate & IGM \\
\hline BYK-103 & Liquid & Dispersant & solution of a copolymer with filler affinic groups & BYK Chemie GmbH \\
\hline
\end{tabular}


Table 2. Designations and corresponding compositions of slurries used in this experiment.

\begin{tabular}{cc}
\hline Designation & Composition \\
\hline 35SN-HDDA & $35 \mathrm{vol} \% \mathrm{Si}_{3} \mathrm{~N}_{4}+\mathrm{Y}_{2} \mathrm{O}_{3}+\mathrm{Al}_{2} \mathrm{O}_{3}+\mathrm{HDDA}$ \\
40SN-HDDA & $40 \mathrm{vol} \% \mathrm{Si}_{3} \mathrm{~N}_{4}+\mathrm{Y}_{2} \mathrm{O}_{3}+\mathrm{Al}_{2} \mathrm{O}_{3}+\mathrm{HDDA}$ \\
$35 \mathrm{SN}-\mathrm{NPG} 2 \mathrm{PODA}$ & $35 \mathrm{vol} . \% \mathrm{Si}_{3} \mathrm{~N}_{4}+\mathrm{Y}_{2} \mathrm{O}_{3}+\mathrm{Al}_{2} \mathrm{O}_{3}+\mathrm{NPG}$ PODA \\
$(10 \mathrm{~S}+25 \mathrm{SN})-\mathrm{HDDA}$ & $10 \mathrm{vol} \% \mathrm{Si}+25 \mathrm{vol} . \% \mathrm{Si}_{3} \mathrm{~N}_{4}+\mathrm{Y}_{2} \mathrm{O}_{3}+\mathrm{Al}_{2} \mathrm{O}_{3}+\mathrm{HDDA}$ \\
$(10 \mathrm{~S}+30 \mathrm{SN})-\mathrm{HDDA}$ & $10 \mathrm{vol} \% \mathrm{Si}+30 \mathrm{vol} . \% \mathrm{Si}_{3} \mathrm{~N}_{4}+\mathrm{Y}_{2} \mathrm{O}_{3}+\mathrm{Al}_{2} \mathrm{O}_{3}+\mathrm{HDDA}$ \\
\hline
\end{tabular}

In this work, the slurries with defined composition were well blended by roll milling. The stereolithography process was conducted by using a commercial Digital Light Processing (DLP) additive manufacturing equipment (Admaflex 130, ADMATEC, The Netherlands), at a humidity of $42 \sim 44 \%$ and a temperature of $26 \sim 28^{\circ} \mathrm{C}$. The transportation of slurry was based on the principle of tape-casting. In this paper, the transport speed was set at 15,000 $\mu \mathrm{m} / \mathrm{s}$ and the gap between blade and transparent foil was controlled at $150 \mu \mathrm{m}$ (corresponding to a shear rate of $100 \mathrm{~s}^{-1}$ ). The printing process was illustrated in Figure 1. Other details involving equipment structure and working principle can be found in our previous work [16].

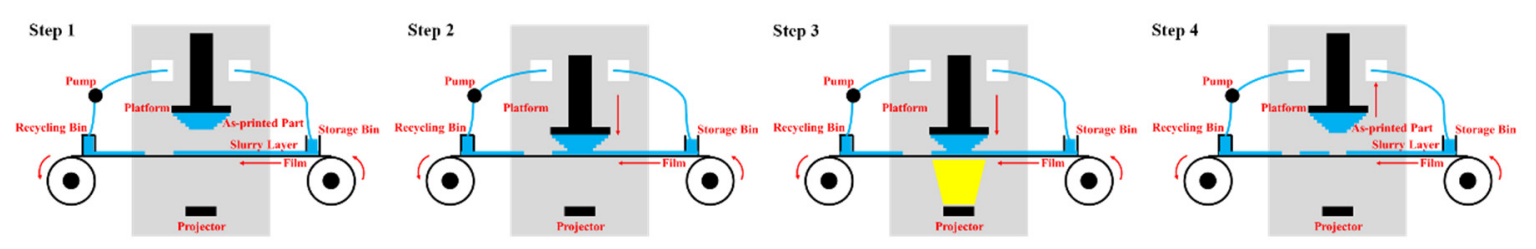

Figure 1. The illustration of the printing process (Step 1: slurry layer is transported, Step 2: platform descends slowly, Step 3: photocure, Step 4: platform rises).

To better understand the flowability of these suspensions, the rheological properties of the fresh $\mathrm{Si}_{3} \mathrm{~N}_{4}$ slurries were analyzed using a rotational rheometer (MCR 301, Anton Paar, Austria). Unless otherwise stated, all the rheological measurements were conducted at $25^{\circ} \mathrm{C}$. The light absorbance of ceramic powders was tested by using an Ultraviolet-visible spectrophotometer (UV-3600, Shimadzu, Japan). The cure depth of the slurries put on small pieces of transparent foils was measured using a digital micrometer after a single exposure (a single-layer-curing method), as illustrated in Figure 2. The exposuring pattern looks like a chess board consisting of a series of squares with its side as $1 \mathrm{~cm}$.

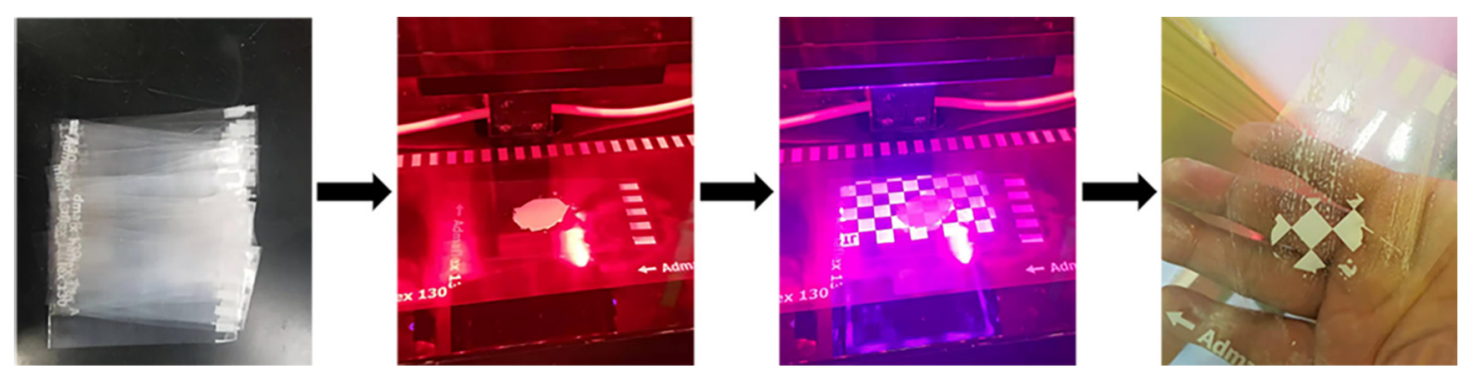

Figure 2. The illustration of the cure depth measurement principle.

\section{Results and Discussion}

\subsection{Rheological Characterization}

Figure 3 shows the flow curves of the slurry where viscosity varies as a function of applied shear rate. Although the pure monomers used in this study were Newtonian fluids and owned low viscosity $(\sim 0.01 \mathrm{~Pa} \cdot \mathrm{s})$, the presence of filler can significantly change the rheological behavior. As shown in Figure 3, all the four slurries exhibited obvious viscosity decrease with increase in the shear rate, 
showing typical shear-thinning characteristic. This kind of non-Newtonian fluid behavior is desirable for the present CSL study, which combines both stereolithography and tape-casting process [40]. It can be seen that the viscosity of (10S + 25SN)-HDDA slurry was much lower than that of 35SN-HDDA slurry. That is, after a portion ( $10 \mathrm{vol} . \%$ ) of fine $\mathrm{Si}_{3} \mathrm{~N}_{4}$ powder in slurry was substituted by the coarse Si powder, the slurry viscosity decreased markedly under the same total solid loading ( $35 \mathrm{vol} . \%)$ and monomer choice (HDDA) conditions. It was because the introduction of Si powder modified the particle size distribution (PSD) from mono-modal $\left(0.5 \mu \mathrm{m} \mathrm{Si}{ }_{3} \mathrm{~N}_{4}\right.$ only) to bimodal distribution $(0.5 \mu \mathrm{m}$ $\mathrm{Si}_{3} \mathrm{~N}_{4}+5 \mu \mathrm{m}$ Si mixture powder), which can decrease the relative viscosity at the same total solid loading according to "Farris effect" [41,42]. As expected, the viscosity increases as the solid loading increases. The viscosity of 40 vol. $\%$ slurry (40SN-HDDA or (10S + 30SN)-HDDA) was observed to be higher than that of 35 vol. $\%$ slurry (35SN-HDDA or (10S + 25SN)-HDDA) in all shear rate regions. Typically, higher molecular weight diacrylates are more viscous, which may be attributed to a larger intermolecular force. It was reported that a lower starting viscosity usually results in a lower final viscosity for the suspension [31]. Accordingly, a lower viscosity can be obtained by using HDDA rather than NPG2PODA as binder when other conditions are identical.

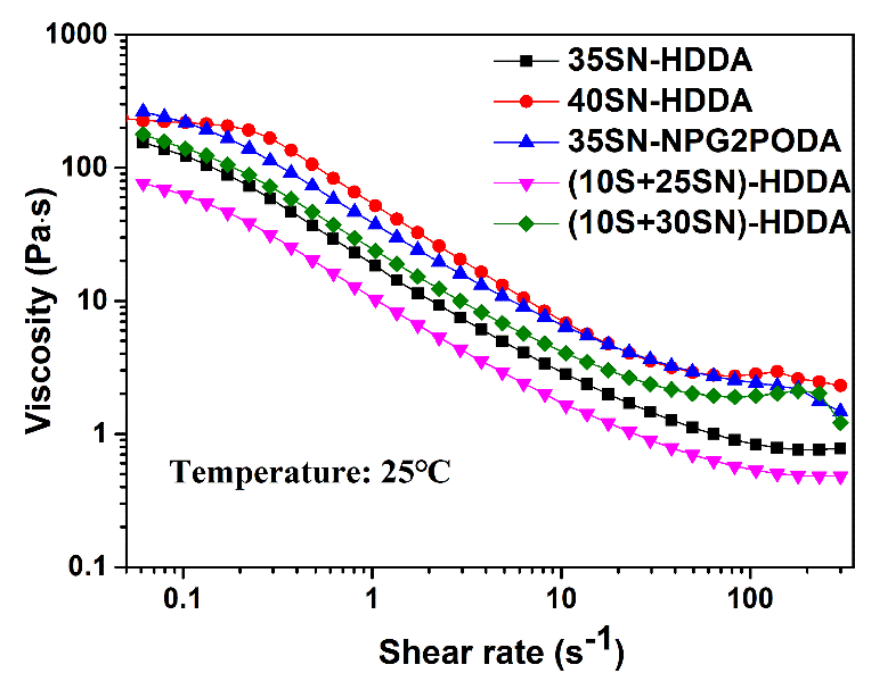

Figure 3. Rheological curves of slurries with different formulation.

Given the seasonal temperature differences in one year, we also used the rheometer MCR 301 to evaluate the rheological behavior of 40SN-HDDA slurry at the temperature range from 5 to $35^{\circ} \mathrm{C}$ with an interval of $10^{\circ} \mathrm{C}$. As expected, a rise of temperature results in a fall in suspensions viscosities (Figure 4). For instance, at $35^{\circ} \mathrm{C}$, the viscosity was reduced by a factor of 14 and drops down to $1.6 \mathrm{~Pa} \cdot \mathrm{s}$ (at the shear rate of $100 \mathrm{~s}^{-1}$ ). Furthermore, the rheological behavior of slurry also showed a strong dependence on temperature. As the shear rate increasing, the viscosity of slurry decreased and reached the plateau faster at lower temperature. In our study, the ambient temperature was kept at $26 \sim 28{ }^{\circ} \mathrm{C}$ which we thought is favorable for a satisfactory layer recoating.

\subsection{Curing Ability Characterization}

Suitable rheological behavior is important for a satisfactory layer recoating and getting homogeneous green body microstructure. In addition, the suspension must exhibit enough curing ability because it is essential to ensure a good connection and cohesion between the photo-polymerized layers. According to Equations (1) and (2), the larger the refractive index difference between ceramic powder and resin, the lower the cure depth. Many researches contributed the difficulty of stereolithography $\mathrm{Si}_{3} \mathrm{~N}_{4}$ to its high refractive index [31,36,43]. However, there are also a few works considering the absorbance of $\mathrm{Si}_{3} \mathrm{~N}_{4}$ powder [35]. Therefore, we firstly characterized the cure depth of slurries with different filler type but same solid loading. As shown in Table 3, for the white-colored system $\left(\mathrm{Al}_{2} \mathrm{O}_{3}\right.$ 
and $\mathrm{ZrO}_{2}$ ), the cure depth decreased significantly with the increase in refractive index of powder. At a relatively low exposure condition (Light intensity: $10 \%$, exposure time: $1.5 \mathrm{~s}$ ), the $\mathrm{Al}_{2} \mathrm{O}_{3}$-slurry's cure depth is more than twice that of $\mathrm{ZrO}_{2}$-slurry. However, when comparing $\mathrm{Si}_{3} \mathrm{~N}_{4}$ - and $\mathrm{ZrO}_{2}$-slurries, it was found that the $\mathrm{Si}_{3} \mathrm{~N}_{4}$ powder filler can make it difficult for the slurry to be curable, although the refractive index of $\mathrm{Si}_{3} \mathrm{~N}_{4}$ is slightly lower than that of $\mathrm{ZrO}_{2}$ and even under an extreme high exposure condition (Light intensity: $80 \%$, exposure time: 10 s) at the meantime.

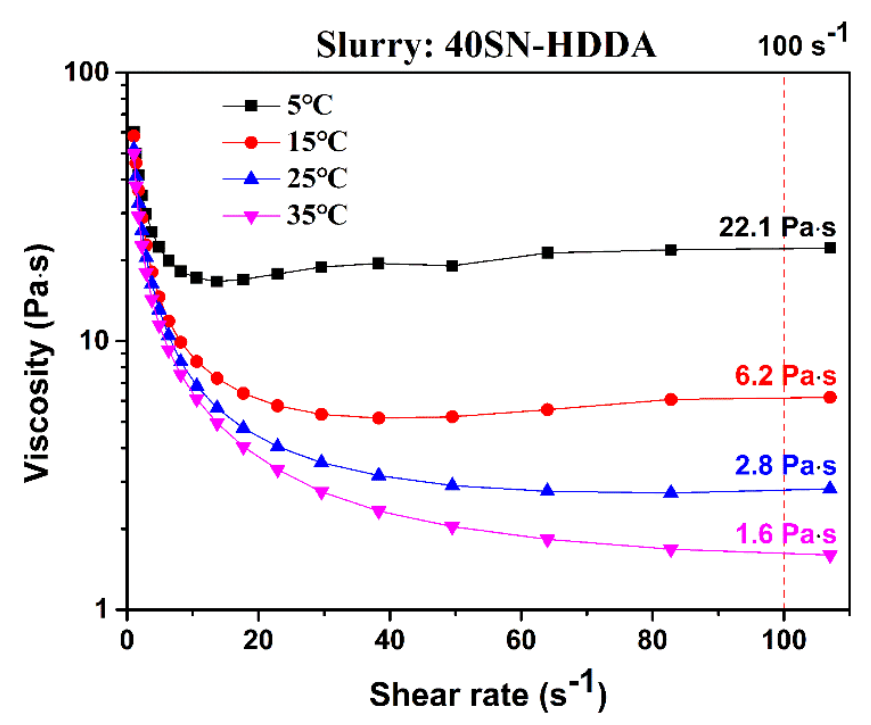

Figure 4. Rheological property of the 40SN-HDDA slurry at different temperature.

Table 3. The influence of powder type with different refractive index on slurry curing ability.

\begin{tabular}{cccccc}
\hline Powder & $\begin{array}{c}\text { Refractive } \\
\text { Index }\end{array}$ & $\begin{array}{c}\text { Solid } \\
\text { Loading/vol.\% }\end{array}$ & $\begin{array}{c}\text { Light } \\
\text { Intensity/\% }\end{array}$ & $\begin{array}{c}\text { Exposure } \\
\text { Time/s }\end{array}$ & $\begin{array}{c}\text { Cure } \\
\text { Depth/ } \boldsymbol{\mu m}\end{array}$ \\
\hline $\mathrm{Al}_{2} \mathrm{O}_{3}$ & 1.77 & 42 & 10 & 1.5 & $121 \pm 4$ \\
$\mathrm{ZrO}_{2}$ & 2.20 & 42 & 10 & 1.5 & $58 \pm 2$ \\
$\mathrm{Si}_{3} \mathrm{~N}_{4}$ (Eno) & 2.10 & 42 & 80 & 10 & $38 \pm 1$ \\
\hline
\end{tabular}

To explain the curing ability differences of $\mathrm{Si}_{3} \mathrm{~N}_{4}$ - and $\mathrm{ZrO}_{2}$-slurries, a simple RGB method was adopted to identify the colors of raw powders referring to Ref. [34]. RGB color mode combines the primary colors, red (R), green $(G)$ and blue (B), in various degrees (ranging from 0 to 255 ) to create a variety of different colors. When all three of the colors are combined and displayed to their full extent, the result is a pure white (R: 255, G: 255, B: 255). Oppositely, it appears pure black (R: 0, G: 0, B: 0). As shown in Figure 5, the Si powder is very dark in color and its RGB values are all small. It can also be seen that these three kinds of $\mathrm{Si}_{3} \mathrm{~N}_{4}$ powders have their different colors, which can be due to different producing processes. Among them, DENKA-Si ${ }_{3} \mathrm{~N}_{4}$ powder has relatively lower RGB values, and its color was a little deeper than those of others accordingly. The colors of $\mathrm{Al}_{2} \mathrm{O}_{3}$ and $\mathrm{ZrO}_{2}$ powders can be viewed as nearly pure white, corresponding to their much higher RGB values.

Similar results were obtained in the absorbance study of powders. The respective absorbance value at $405 \mathrm{~nm}$ (i.e., the wavelength of the 3D printer's light source) was listed in Figure 6 for comparison. It can be seen that in the visible light wavelength range, the deeper the powder's color, the higher the absorbance value. The absorbance values of white $\mathrm{Al}_{2} \mathrm{O}_{3}$ and $\mathrm{ZrO}_{2}$ powders were near zero, so these two materials should be transparent to the radiation in this experiment. Consequently, the low curing ability of $\mathrm{ZrO}_{2}$ in comparison with $\mathrm{Al}_{2} \mathrm{O}_{3}$ can be largely attributed to its high refractive index [44,45]. For ceramic stereolithography, the solidification of slurries depends on how much "out-put" light energy will reach to the resin itself, which could trigger photo-crosslinking reaction and subsequently bind the powder together to form the parts with desired shape. Therefore, the larger the absorbance 
of powder, the less light energy will act on the photosensitive resin, and the worse the curing ability will exhibit [34]. As Figure 6 shows, in addition to the high refractive index, the absorbance of $\mathrm{Si}_{3} \mathrm{~N}_{4}$ powder also should not be ignored. As a result, the stereolithography of $\mathrm{Si}_{3} \mathrm{~N}_{4}$ is more difficult than that of $\mathrm{ZrO}_{2}$ and seldom reported. Unless otherwise specified, the Eno- $\mathrm{Si}_{3} \mathrm{~N}_{4}$ powder was selected as the filler in slurries because it owns low absorbance.

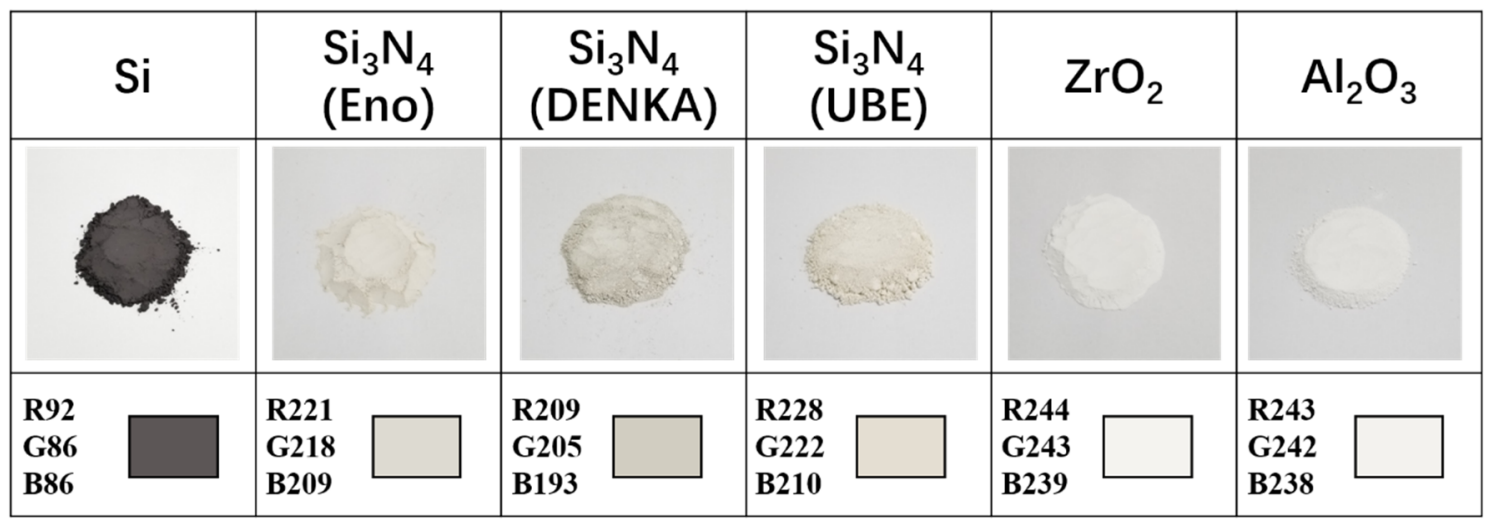

Figure 5. Colors and RGB values of raw powders.

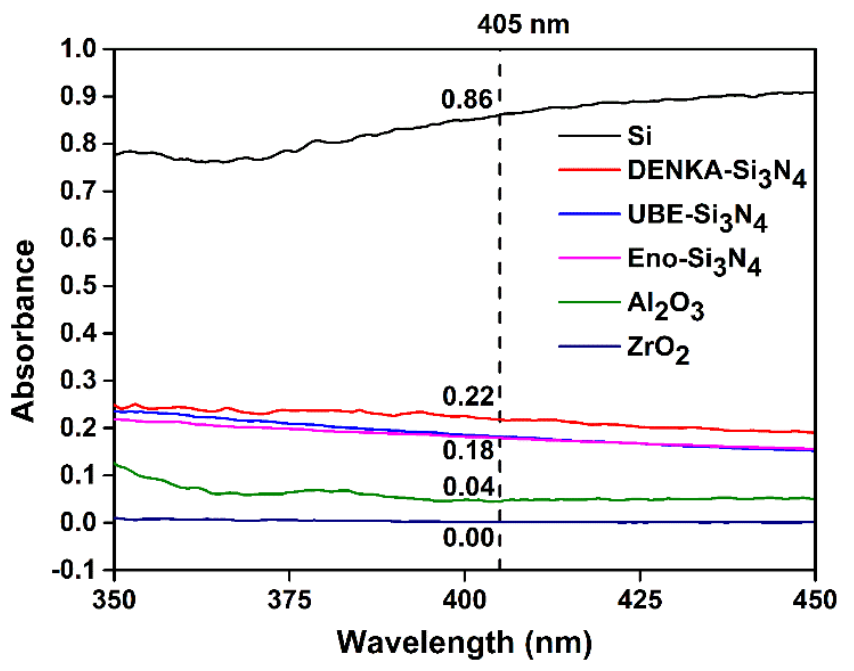

Figure 6. The absorbance of raw powders.

Figure 7 shows the cure depth results and corresponding optical pictures of different slurries. For the ceramic printer Adamaflex 130, about $0.58 \mathrm{~mW} / \mathrm{cm}^{2}$ corresponds to a percentage of the light intensity. As predicted, the cure depth gradually increases as exposure energy dose increases (Figure 7a,d). According to Equation (1), the cure depth has a linear correlation with the mean particle size. This was studied and reported in many papers by numerical model [46] and conducting experiments [34]. However, the larger grain can impose negative impact on the mechanical performance of structural ceramics in agreement with the Hall-Petch relationship [47]. Due to the grain growth during the densification process, researchers tend to use the as-received powder with a size of nano- to submicronmeter to produce high-performance ceramic materials. As for the fabrication of $\mathrm{Si}_{3} \mathrm{~N}_{4}$ ceramics, a forming method named sintered reaction-bonded silicon nitride (SRBSN) is well-known, which uses the relative cheaper Si raw powders instead of $\mathrm{Si}_{3} \mathrm{~N}_{4}$ powder [48]. Herein, we replaced a portion of $\mathrm{Si}_{3} \mathrm{~N}_{4}$ powder with the coarse $5 \mu \mathrm{m}$ Si powder to see whether it can help to improve the curing ability of slurries. Figure $7 \mathrm{a}-\mathrm{c}$ shows the results of the slurries with a mixture of silicon and $\mathrm{Eno}-\mathrm{Si}_{3} \mathrm{~N}_{4}$ powder. It can be seen that a higher solid loading can result in a lower cure depth. However, even under an extreme high exposure condition (light intensity: 70\%, exposure time: $40 \mathrm{~s}$, energy density: $1.61 \mathrm{~J} / \mathrm{cm}^{2}$ ) the cure 
depth of slurries containing silicon powder was still extreme low (less than $7 \mu \mathrm{m}$ ) when compared with those slurries without containing silicon powder. It can be attributed to the higher absorbance of silicon powder $(0.86$ at $405 \mathrm{~nm})$ than that of $\mathrm{Si}_{3} \mathrm{~N}_{4}$ powder $(0.18$ at $405 \mathrm{~nm})$. As shown in Figure $7 \mathrm{~d}$, for the slurries without silicon powder, using NPG2PODA as crosslinking agent can obtain a higher cure depth than that of using HDDA at the same condition. In the meantime, however, it can be seen in Figure 7e,f that a more serious "over-cure" phenomenon in the lateral direction can be observed with the naked eye by adding NPG2PODA. This result, appearing as the probable cause of the higher molecular weight which NPG2PODA possesses, deserves further investigation and will be discussed in our future work.

(a)

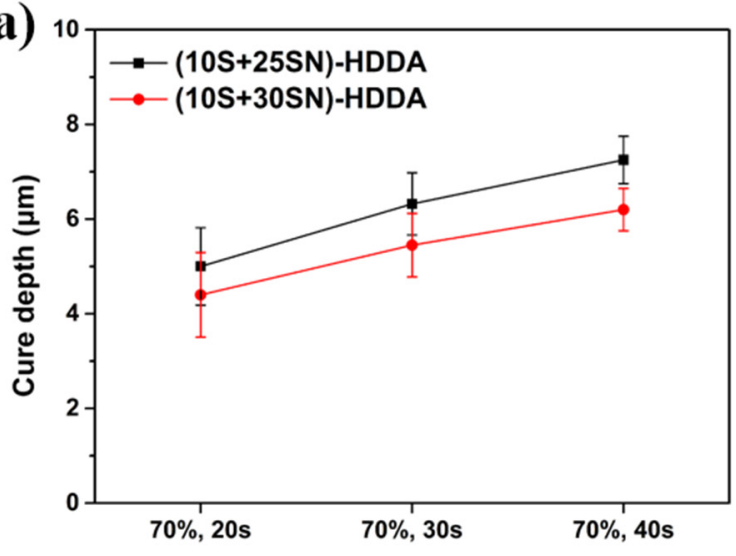

Light intensity (\%), exposure time (s)

(d)

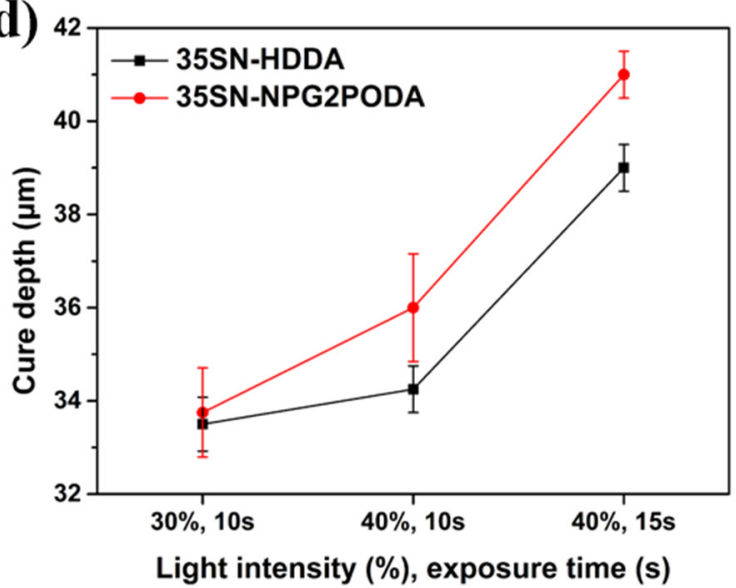

(b)

(10S+25SN)-HDDA Light intensity: $70 \%$ Exposure time: $40 \mathrm{~s}$

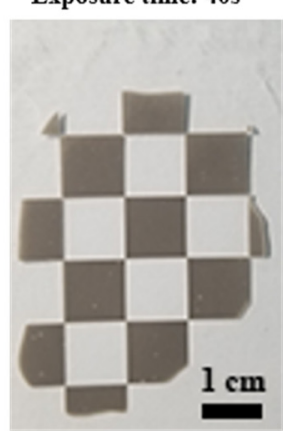

(e)

35SN-HDDA Light intensity: $\mathbf{4 0} \%$ Exposure time: $15 \mathrm{~s}$

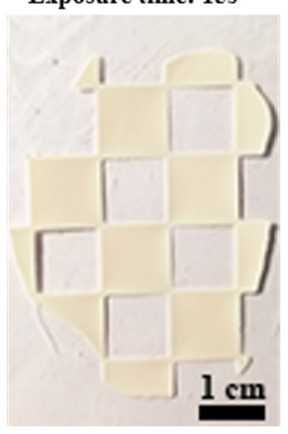

(c)

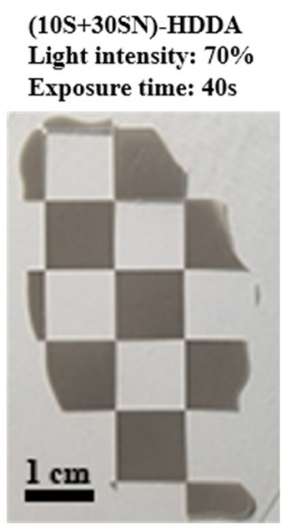

(f)

35SN-NPG2PODA Light intensity: $40 \%$ Exposure time: 15s

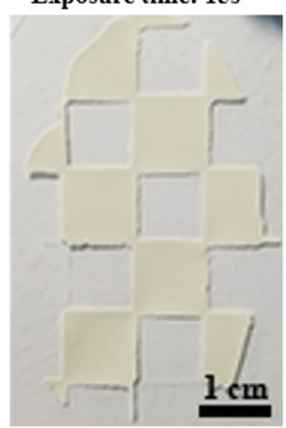

Figure 7. (a) Cure depth vs. exposure parameters for $(10 \mathrm{~S}+25 \mathrm{SN})$-HDDA and $(10 \mathrm{~S}+30 \mathrm{SN})$-HDDA slurries with their respective optical pictures ((b,c), light intensity: 70\%, exposure time: 40 s, energy density: $1.61 \mathrm{~J} / \mathrm{cm}^{2}$ ). (d) Cure depth vs. exposure parameters for 35SN-HDDA and 35SN-NPG2PODA slurries with their respective optical pictures ((e,f), light intensity: $40 \%$, exposure time: $15 \mathrm{~s}$, energy density: $\left.0.35 \mathrm{~J} / \mathrm{cm}^{2}\right)$.

Based on the as-obtained $\mathrm{Si}_{3} \mathrm{~N}_{4}$ slurry (35SN-HDDA), stereolithography-based additive manufacturing was conducted. The printing parameters were set as 30\% for the light intensity, $10 \mathrm{~s}$ for the exposure time and $20 \mu \mathrm{m}$ for the layer thickness in this work. Figure 8 presents the stereolithography of both complex-shaped parts and cuboid-like samples for testing. For the cuboid test bar, the design sizes of length, width and height were $11 \mathrm{~mm}, 5 \mathrm{~mm}$ and $4 \mathrm{~mm}$, respectively. The measured values of length, width and height were $11.47 \pm 0.05 \mathrm{~mm}, 5.64 \pm 0.04 \mathrm{~mm}$ and $3.94 \pm 0.04 \mathrm{~mm}$, respectively. It can be seen that the lateral precision of the $\mathrm{Si}_{3} \mathrm{~N}_{4}$ bars decreased, which was caused by the scattering of light. The study of binder burn-out and sintering, as well as mechanical performance, has to be further investigated in more detail in our future work. 


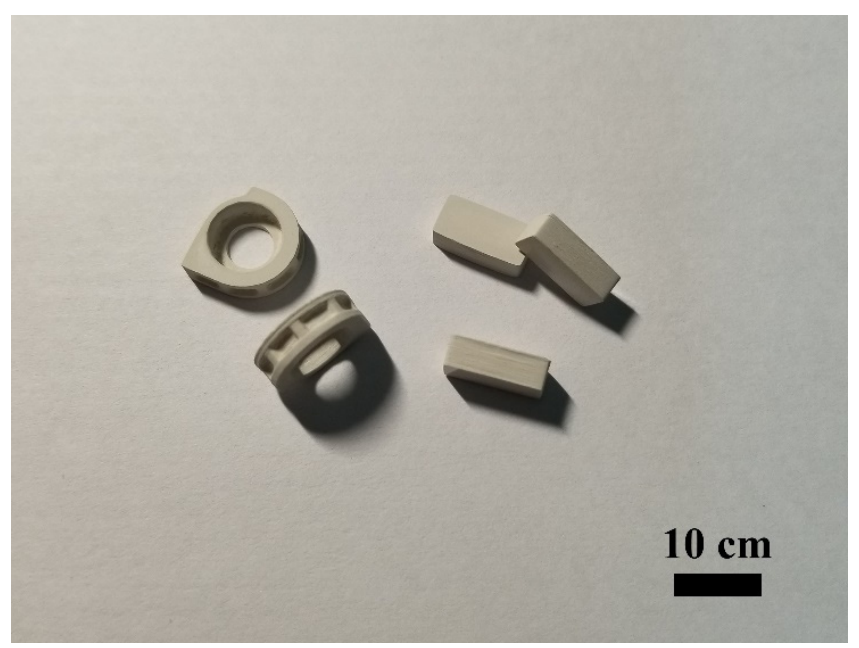

Figure 8. The stereolithography of $\mathrm{Si}_{3} \mathrm{~N}_{4}$ ceramic architectures with complex shape and simple cuboid structures.

\section{Conclusions}

In this work, $\mathrm{Si}_{3} \mathrm{~N}_{4}$ ceramic was shaped using a stereolithography-based additive manufacturing technique. The slurry performance was intensively studied based on the analysis of rheological and curing ability measurements. Main conclusions are listed as follows,

(1) The presence of filler can significantly change the rheological behavior of pure monomers from Newtonian fluid to shear-thinning characteristic. Choosing the monomer with low molecular weight and taking the particle grading into consideration can obtain lower slurry viscosity.

(2) The viscosity of $\mathrm{Si}_{3} \mathrm{~N}_{4}$ photocurable slurries were greatly affected by ambient temperature. With the temperature increased, the viscosity decreased obviously. Therefore, in this work the temperature was set as $25^{\circ} \mathrm{C}$ which we think was suitable for machine handling.

(3) $\mathrm{The}_{3} \mathrm{~N}_{4}$ slurry had lower curing ability when compared with oxide ceramic slurries. Because, besides the large refractive index of $\mathrm{Si}_{3} \mathrm{~N}_{4}$, it was measured that the absorbance of $\mathrm{Si}_{3} \mathrm{~N}_{4}$ powder also should not be ignored. According to the derivative equation from Beer-Lambert law, the cure depth is proportional to particle size. The coarse silicon powder with a particle size of $5 \mu \mathrm{m}$ was introduced to try improving curing ability but failed. It is because that silicon powder has a much higher absorbance. Using NPG2PODA as crosslinking agent can obtain a higher cure depth than that of using HDDA at the same condition. This appearing as the probable cause of the higher molecular weight which NPG2PODA possesses.

Through the analysis of rheological and curing ability of slurries, the complex-shaped $\mathrm{Si}_{3} \mathrm{~N}_{4}$ ceramic could be manufactured using the stereolithography technology. The authors believe that this paper can give some thinking for the additive manufacturing of $\mathrm{Si}_{3} \mathrm{~N}_{4}$ or other non-oxide ceramics.

Author Contributions: Conceptualization, X.L. (Xingbang Li) and J.Z.; Data curation, X.L. (Xingbang Li) and N.L.; Formal analysis, X.L. (Xingbang Li), Y.D., N.L. and R.M.; Funding acquisition, J.Z., H.X., X.L. (Xiaoguang Li); Investigation, X.L. (Xingbang Li); Methodology, X.L. (Xingbang Li); Project administration, J.Z., H.X., X.L. (Xiaoguang Li); Software, Y.D. and J.J.; Supervision, J.Z.; Visualization, X.L. (Xingbang Li); Writing-original draft, X.L. (Xingbang Li); Writing-review \& editing, X.L. (Xingbang Li) and J.Z. All authors have read and agreed to the published version of the manuscript.

Funding: This research was funded by the National Key Research and Development Program of China (2017YFB-0310400), National Natural Science Foundation of China (No. 51572277, 51702340) and Shanghai Science and Technology Committee (17YF1428800, 17ZR1434800, 17dz2307000). And the APC was funded by the National Key Research and Development Program of China (2017YFB-0310400).

Acknowledgments: The authors acknowledge the State Key Laboratory of High Performance Ceramics and Superfine Microstructure of Shanghai Institute Ceramics, Chinese Academy of Sciences, and Foshan Research and Development Center for Ceramics. 
Conflicts of Interest: The authors declare no conflict of interest.

\section{References}

1. Riley, F.L. Silicon Nitride and Related Materials. J. Am. Ceram. Soc. 2004, 83, 245-265. [CrossRef]

2. Zhu, X.; Sakka, Y. Textured silicon nitride: Processing and anisotropic properties. Sci. Technol. Adv. Mater. 2008, 9, 33001. [CrossRef] [PubMed]

3. Tajima, Y. Development of High Performance Silicon Nitride Ceramics and their Applications. MRS Proc. 1992, 287, 189. [CrossRef]

4. Zhou, Y.; Hyuga, H.; Kusano, D.; Yoshizawa, Y.-I.; Ohji, T.; Hirao, K. Development of high-thermalconductivity silicon nitride ceramics. J. Asian Ceram. Soc. 2015, 3, 221-229. [CrossRef]

5. Yokota, H.; Ibukiyama, M. Effect of the addition of $\beta-S_{3} \mathrm{~N}_{4}$ nuclei on the thermal conductivity of $\beta-\mathrm{Si}_{3} \mathrm{~N}_{4}$ ceramics. J. Eur. Ceram. Soc. 2003, 23, 1183-1191. [CrossRef]

6. Hampshire, S.; Pomeroy, M.J. Grain boundary glasses in silicon nitride: A review of chemistry, properties and crystallisation. J. Eur. Ceram. Soc. 2012, 32, 1925-1932. [CrossRef]

7. Chen, Z.; Li, Z.; Li, J.; Liu, C.; Lao, C.; Fu, Y.; Liu, C.; Li, Y.; Wang, P.; He, Y.; et al. 3D printing of ceramics: A review. J. Eur. Ceram. Soc. 2019, 39, 661-687. [CrossRef]

8. Halloran, J.W. Ceramic Stereolithography: Additive Manufacturing for Ceramics by Photopolymerization. Annu. Rev. Mater. Res. 2016, 46, 19-40. [CrossRef]

9. Schmidt, J.; Colombo, P. Digital light processing of ceramic components from polysiloxanes. J. Eur. Ceram. Soc. 2018, 38, 57-66. [CrossRef]

10. Wu, H.; Cheng, Y.; Liu, W.; He, R.; Zhou, M.; Wu, S.; Song, X.; Chen, Y. Effect of the particle size and the debinding process on the density of alumina ceramics fabricated by $3 \mathrm{D}$ printing based on stereolithography. Ceram. Int. 2016, 42, 17290-17294. [CrossRef]

11. Li, W.; Liu, W.; Qi, F.; Chen, Y.; Xing, Z. Determination of micro-mechanical properties of additive manufactured alumina ceramics by nanoindentation and scratching. Ceram. Int. 2019, 45, 10612-10618. [CrossRef]

12. Schwentenwein, M.; Homa, J. Additive Manufacturing of Dense Alumina Ceramics. Int. J. Appl. Ceram. Technol. 2014, 12, 1-7. [CrossRef]

13. Zhang, K.; Xie, C.; Wang, G.; He, R.; Ding, G.; Wang, M.; Dai, D.; Fang, D. High solid loading, low viscosity photosensitive $\mathrm{Al}_{2} \mathrm{O}_{3}$ slurry for stereolithography based additive manufacturing. Ceram. Int. 2019, 45, 203-208. [CrossRef]

14. Wu, X.; Lian, Q.; Li, D.; He, X.; Liu, X.; Meng, J.; Jin, Z. Effects of soft-start exposure on the curing characteristics and flexural strength in ceramic projection stereolithography process. J. Eur. Ceram. Soc. 2019, 39, 3788-3796. [CrossRef]

15. Xu, X.; Zhou, S.; Wu, J.; Zhang, Q.; Zhang, Y.; Zhu, G. Preparation of highly dispersive solid microspherical $\alpha-\mathrm{Al}_{2} \mathrm{O}_{3}$ powder with a hydrophobic surface for stereolithography-based 3D printing technology. Ceram. Int. 2020, 46, 1895-1906. [CrossRef]

16. Li, X.; Zhong, H.; Zhang, J.; Duan, Y.; Li, J.; Jiang, D. Fabrication of zirconia all-ceramic crown via DLP-based stereolithography. Int. J. Appl. Ceram. Technol. 2019, 17, 844-853. [CrossRef]

17. Fu, X.; Zou, B.; Xing, H.; Li, L.; Li, Y.; Wang, X. Effect of printing strategies on forming accuracy and mechanical properties of $\mathrm{ZrO}_{2}$ parts fabricated by SLA technology. Ceram. Int. 2019, 45, 17630-17637. [CrossRef]

18. He, R.; Liu, W.; Wu, Z.; An, D.; Huang, M.; Wu, H.; Jiang, Q.; Ji, X.; Wu, S.; Xie, Z. Fabrication of complexshaped zirconia ceramic parts via a DLP-stereolithography-based 3D printing method. Ceram. Int. 2018, 44, 3412-3416. [CrossRef]

19. Li, X.; Zhong, H.; Zhang, J.; Duan, Y.; Bai, H.; Li, J.; Jiang, D. Dispersion and properties of zirconia suspensions for stereolithography. Int. J. Appl. Ceram. Technol. 2019, 17, 239-247. [CrossRef]

20. Sun, J.; Binner, J.; Bai, J. Effect of surface treatment on the dispersion of nano zirconia particles in non-aqueous suspensions for stereolithography. J. Eur. Ceram. Soc. 2019, 39, 1660-1667. [CrossRef]

21. Wu, H.; Liu, W.; He, R.; Wu, Z.; Jiang, Q.; Song, X.; Chen, Y.; Cheng, L.; Wu, S. Fabrication of dense zirconia-toughened alumina ceramics through a stereolithography-based additive manufacturing. Ceram. Int. 2017, 43, 968-972. [CrossRef] 
22. Liu, X.; Zou, B.; Xing, H.; Huang, C. The preparation of $\mathrm{ZrO}_{2}-\mathrm{Al}_{2} \mathrm{O}_{3}$ composite ceramic by SLA-3D printing and sintering processing. Ceram. Int. 2020, 46, 937-944. [CrossRef]

23. Xing, H.; Zou, B.; Liu, X.; Wang, X.; Chen, Q.; Fu, X.; Li, Y. Effect of particle size distribution on the preparation of ZTA ceramic paste applying for stereolithography 3D printing. Powder Technol. 2020, 359, 314-322. [CrossRef]

24. Wang, Y.; Wang, Z.; Liu, S.; Qu, Z.; Han, Z.; Liu, F.; Li, L. Additive manufacturing of silica ceramics from aqueous acrylamide based suspension. Ceram. Int. 2019, 45, 21328-21332. [CrossRef]

25. Chartier, T.; Badev, A.; Abouliatim, Y.; Lebaudy, P.; Lecamp, L. Stereolithography process: Influence of the rheology of silica suspensions and of the medium on polymerization kinetics-Cured depth and width. J. Eur. Ceram. Soc. 2012, 32, 1625-1634. [CrossRef]

26. Bae, C.-J.; Kim, D.; Halloran, J.W. Mechanical and kinetic studies on the refractory fused silica of integrally cored ceramic mold fabricated by additive manufacturing. J. Eur. Ceram. Soc. 2018, 39, 618-623. [CrossRef]

27. Lasgorceix, M.; Champion, E.; Chartier, T. Shaping by microstereolithography and sintering of macro-micro-porous silicon substituted hydroxyapatite. J. Eur. Ceram. Soc. 2016, 36, 1091-1101. [CrossRef]

28. Wang, Z.; Huang, C.; Wang, J.; Zou, B. Development of a novel aqueous hydroxyapatite suspension for stereolithography applied to bone tissue engineering. Ceram. Int. 2019, 45, 3902-3909. [CrossRef]

29. Pfaffinger, M.; Hartmann, M.; Schwentenwein, M.; Stampfl, J. Stabilization of tricalcium phosphate slurries against sedimentation for stereolithographic additive manufacturing and influence on the final mechanical properties. Int. J. Appl. Ceram. Technol. 2017, 14, 499-506. [CrossRef]

30. Chen, Z.; Liu, C.; Li, J.; Zhu, J.; Liu, Y.; Lao, C.; Feng, J.; Jiang, M.; Liu, C.; Wang, P.; et al. Mechanical properties and microstructures of 3D printed bulk cordierite parts. Ceram. Int. 2019, 45, 19257-19267. [CrossRef]

31. Griffith, M.L.; Halloran, J.W. Freeform Fabrication of Ceramics via Stereolithography. J. Am. Ceram. Soc. 2005, 79, 2601-2608. [CrossRef]

32. Griffith, M.L.; Halloran, J.W. Scattering of ultraviolet radiation in turbid suspensions. J. Appl. Phys. 1997, 81, 2538-2546. [CrossRef]

33. He, R.; Ding, G.; Zhang, K.; Li, Y.; Fang, D. Fabrication of SiC ceramic architectures using stereolithography combined with precursor infiltration and pyrolysis. Ceram. Int. 2019, 45, 14006-14014. [CrossRef]

34. Ding, G.; He, R.; Zhang, K.; Xie, C.; Wang, M.; Yang, Y.; Fang, D. Stereolithography-based additive manufacturing of gray-colored SiC ceramic green body. J. Am. Ceram. Soc. 2019, 102, 7198-7209. [CrossRef]

35. Huang, R.-J.; Jiang, Q.-G.; Wu, H.-D.; Li, Y.-H.; Liu, W.-Y.; Lu, X.-X.; Wu, S. Fabrication of complex shaped ceramic parts with surface-oxidized $\mathrm{Si}_{3} \mathrm{~N}_{4}$ powder via digital light processing based stereolithography method. Ceram. Int. 2019, 45, 5158-5162. [CrossRef]

36. Liu, Y.; Zhan, L.; He, Y.; Zhang, J.; Hu, J.; Cheng, L.; Wu, Q.; Liu, S. Stereolithographical fabrication of dense $\mathrm{Si}_{3} \mathrm{~N}_{4}$ ceramics by slurry optimization and pressure sintering. Ceram. Int. 2020, 46, 2063-2071. [CrossRef]

37. Wang, M.; Xie, C.; He, R.; Ding, G.; Zhang, K.; Wang, G.; Fang, D. Polymer-derived silicon nitride ceramics by digital light processing based additive manufacturing. J. Am. Ceram. Soc. 2019, 102, 5117-5126. [CrossRef]

38. Krstic, Z.; Krstic, V.D. Silicon nitride: The engineering material of the future. J. Mater. Sci. 2011, 47, 535-552. [CrossRef]

39. Yang, J.-F.; Ohji, T.; Niihara, K. Influence of Yttria-Alumina Content on Sintering Behavior and Microstructure of Silicon Nitride Ceramics. J. Am. Ceram. Soc. 2004, 83, 2094-2096. [CrossRef]

40. Hinczewski, C.; Corbel, S.; Chartier, T. Ceramic suspensions suitable for stereolithography. J. Eur. Ceram. Soc. 1998, 18, 583-590. [CrossRef]

41. Greenwood, R.; Luckham, P.F.; Gregory, T. Minimising the viscosity of concentrated dispersions by using bimodal particle size distributions. Colloids Surf. A Physicochem. Eng. Asp. 1998, 144, 139-147. [CrossRef]

42. Bae, C.-J.; Halloran, J.W. Concentrated suspension-based additive manufacturing-viscosity, packing density, and segregation. J. Eur. Ceram. Soc. 2019, 39, 4299-4306. [CrossRef]

43. Altun, A.A.; Prochaska, T.; Konegger, T.; Schwentenwein, M. Dense, Strong, and Precise Silicon Nitride-Based Ceramic Parts by Lithography-Based Ceramic Manufacturing. Appl. Sci. 2020, 10, 996. [CrossRef]

44. Yanhui, L.; Yong, C.; Minglang, W.; Lian, L.; Haidong, W.; Fupo, H.; Wu, S. The cure performance of modified $\mathrm{ZrO}_{2}$ coated by paraffin via projection based stereolithography. Ceram. Int. 2019, 45, 4084-4088. [CrossRef]

45. Song, X.; Chen, Y.; Lee, T.-W.; Wu, S.; Cheng, L. Ceramic fabrication using Mask-Image-Projection-based Stereolithography integrated with tape-casting. J. Manuf. Process. 2015, 20, 456-464. [CrossRef]

46. Sun, C.; Zhang, X. The influences of the material properties on ceramic micro-stereolithography. Sens. Actuators A Phys. 2002, 101, 364-370. [CrossRef] 
47. An, D.; Li, H.; Xie, Z.; Zhu, T.; Luo, X.; Shen, Z.; Ma, J. Additive manufacturing and characterization of complex $\mathrm{Al}_{2} \mathrm{O}_{3}$ parts based on a novel stereolithography method. Int. J. Appl. Ceram. Technol. 2017, 14, 836-844. [CrossRef]

48. Lee, S.-H.; Cho, C.-R.; Park, Y.-J.; Ko, J.-W.; Kim, H.-D.; Lin, H.-T.; Becher, P. Densification of Reaction Bonded Silicon Nitride with the Addition of Fine Si Powder-Effects on the Sinterability and Mechanical Properties. J. Korean Ceram. Soc. 2013, 50, 218-225. [CrossRef]

C 2020 by the authors. Licensee MDPI, Basel, Switzerland. This article is an open access article distributed under the terms and conditions of the Creative Commons Attribution (CC BY) license (http://creativecommons.org/licenses/by/4.0/). 